\title{
THE DESIGN INSIDERS
}

Profiling design roles and functions within Scotland's top 500 companies

By lain Aitchison, Sam Dunne and Esther Steiner

2,824 words

\section{INTRODUCTION}

There are more than one million people working in in-house design jobs in the UK; three times more than in creative agencies or consulting firms (Design Council, 2015). But who are they, where do they work and what type of roles do they have?

In recent years many efforts have been made by organisations internationally - such as the Design Management Institute, UK Design Council and Danish Design Council - to understand the contribution of design to business, both at a company and country levels. Some have focussed on evidencing the value of and return on design investment by businesses, others on benchmarking the relative 'maturity' of companies' use of design. More recent work by consulting firms like McKinsey and InVision profile the attributes of successful in-house design leadership. These efforts can be seen as part of a broader movement to once-and-for-all cement design's place as a core business function alongside its more established cousins in marketing, $R \& D$, sales and finance.

Despite this, little large scale work has been done to understand the legions of individual designers working in-house, the range of jobs they do within different sectors, and how these roles are organised into varying forms of in-house design function. Therefore this project takes as its starting point the individual employees that make up the growing number of in-house design organisations across all sectors of the economy. 


\section{DESIGN ROLES}

To a global audience Scotland may be best known for its most famous export, whisky. However, a glance at most yearly rankings of its top ten companies shows it to be a nation of greater economic diversity and strength than first meets the eye: with a range of global players in financial services, energy and engineering sectors reporting multi-billion dollar turnovers and tens of thousands of staff globally. But to what extent do these top companies employ designers in-house?

The Business Insider Top 500 is an annual survey of Scotland's largest 500 companies ranked by turnover and profit (Business Insider, 2018). By taking this list as a starting point, this project performed a company-by-company search of professional social media site Linkedln to record the incidence of employees with design-related job titles. From this research it was found that 40 per cent of the top 500 companies in Scotland, have employees performing in-house design roles (Figure 1). Although these in-house roles are found across all sectors of the economy; companies in energy production, financial services, IT and extraction industries are more likely to have designers in in-house roles than those in other sectors.

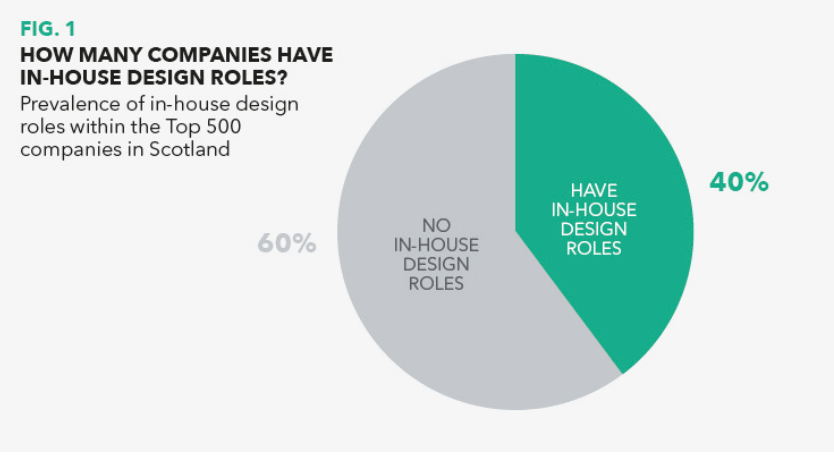

Within the 200 companies employing designers in-house an estimated 1,737 people in design roles were identified through this research. But what roles do these in-house designers actually fulfil? By performing a bottom-up 'grounded-style' coding approach, hundreds of different job titles were identified from the 1,737 designers researched. These job titles were then further coded into 17 types of in-house design roles. To describe the range of abilities and disciplines of design represented by these roles, an adapted version of Richard Buchanan's 'Four Orders of Design' framework (Buchanan, 1998) was used to structure them into four categories (Figure 3).

FIG. 3.0

WHICH JOBS ROLES ARE IN-HOUSE DESIGNERS PERFORMING?

Breakdown of design role types within each order of design

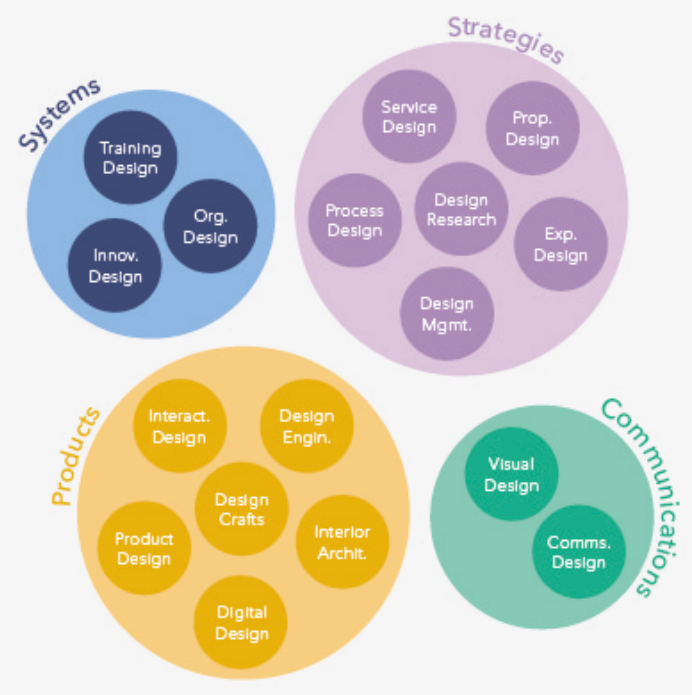


By looking at job titles in this way it has been possible to survey and frame a broad landscape of contemporary in-house design practice. From those in-house designers working on

communications; or those designing products; to designers using their skills as design researchers, design managers or service designers to give form to company strategies; to a nascent band of in-house design pioneers working on the integration of design into the systems of companies, be it in re-designing innovation processes, training employees in a design approaches, or even helping to re-design organisations themselves.

As well as understanding the proportion of in-house designers working in each order of design (Figure 3.1), an understanding has been reached on the number of designers employed across each design role today (Figure 3.2).

FIG. 3.1

WHAT TYPES OF ROLES DO IN-HOUSE DESIGNERS HAVE?

Breakdown of in-house design roles within the Top 500 companies in Scotland by order of design
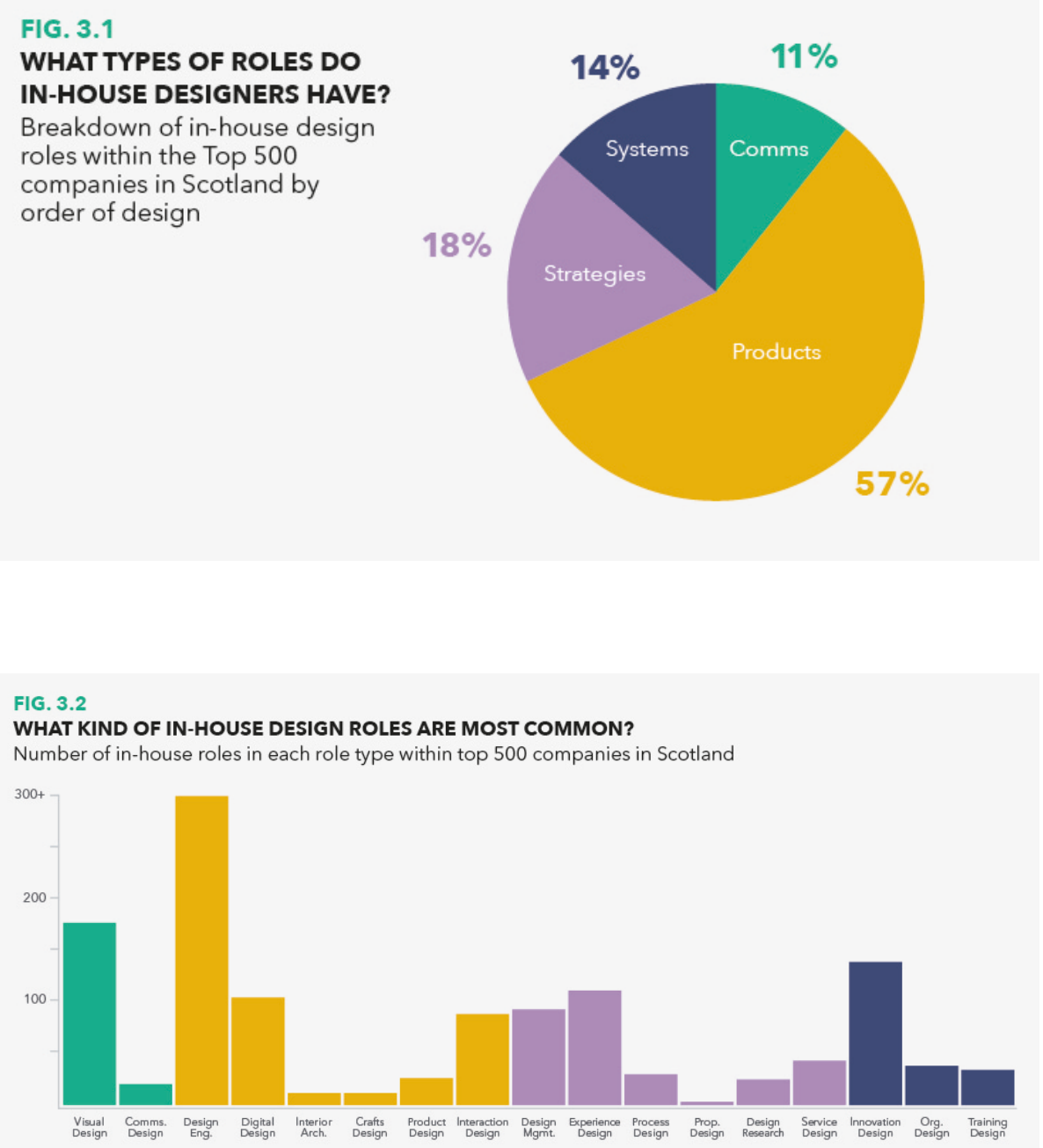


\section{DESIGN FUNCTION ARCHETYPES}

How then are these roles organised into different types of in-house design function? By analysing the incidence, concentration and scope of the 17 design roles across all companies with in-house design functions, a framework of 12 design function 'archetypes' of varying scopes and sizes have been defined (see Figure 4).
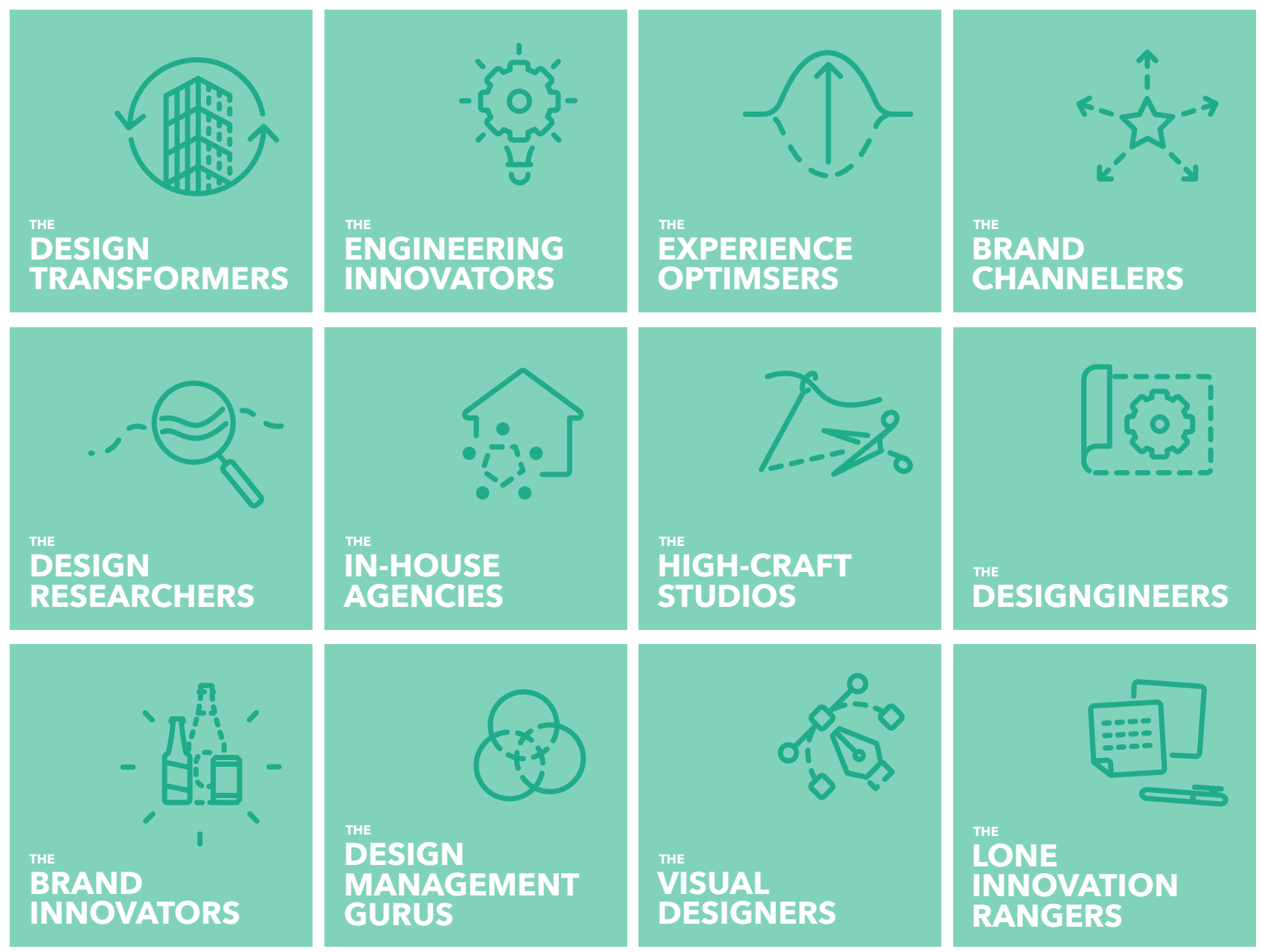

FIG. 4

HOW BIG ARE THESE IN-HOUSE DESIGN FUNCTIONS?

Average size of design function (number of people)

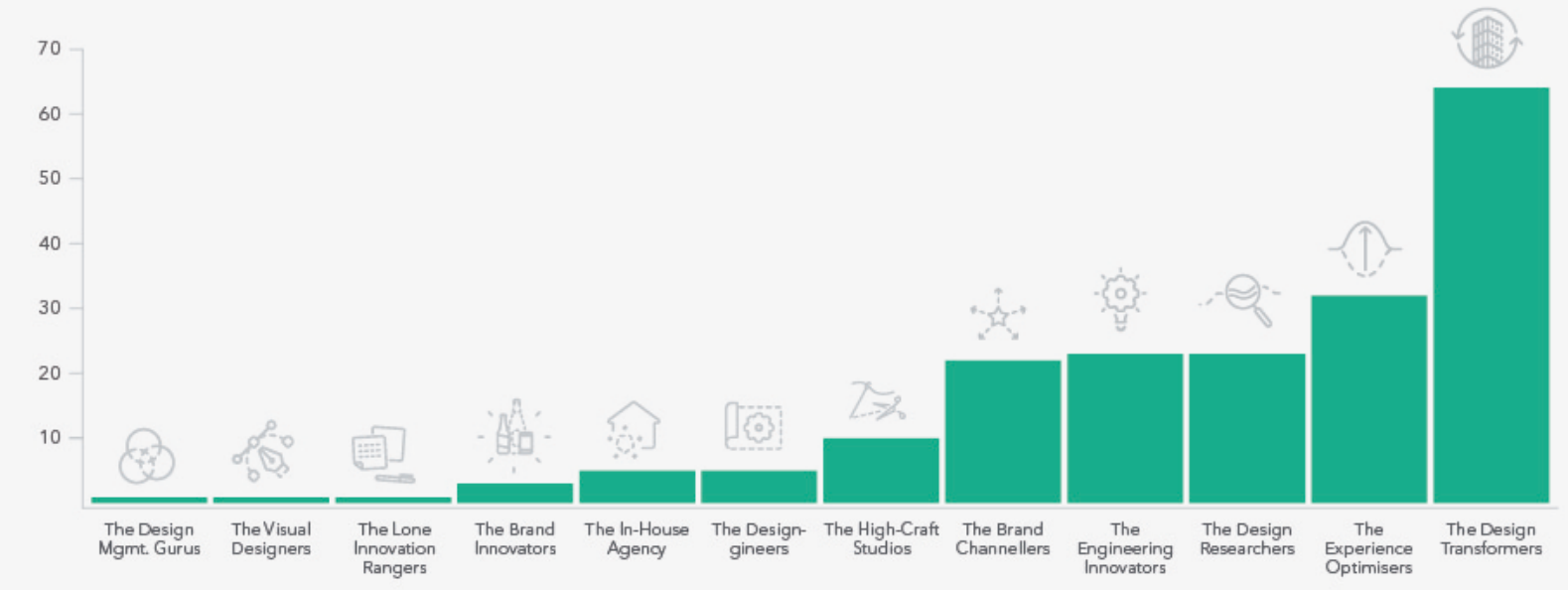




\section{THE DESIGN TRANSFORMERS}

\section{DESCRIPTION}

The heavyweight of design function configurations. Predominantly seen within established service sectors like financial services and energy supply; these design battalions are found in incumbent industry behemoths attempting to transform both their offer and operating models in the face of emerging competition, evolving customer expectations and shifting regulatory landscapes. Design here is tasked with rewiring a business from inside out. While all share a design-led transformation agenda, examples vary between centralised and decentralised models: centralisers gathering design, innovation and transformation capabilities in an internal centre of expertise; with their decentralised counterparts embedding this expertise at the coalface of relevant departments and business units.

\section{LEADERSHIP CHALLENGES}

- How can large centralised design teams best position their expertise relative to other internal teams and external consulting agencies, who also lay claim to the transformation agenda?

- How can decentralised teams complement their proximity to business decisions with the ability to share best-practice with other pockets of design practice in the organisation?

- How can multiple design career paths be created to allow team members to develop in either managerial or creative specialist routs of progression?

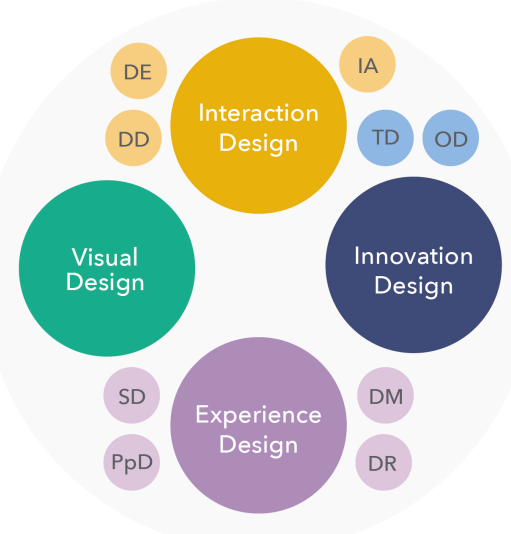

\section{THE ENGINEERING INNOVATORS}

\section{DESCRIPTION}

The crusaders of the brave new world of global engineering solutions provision. This design profile is common amongst legacy manufacturers of specialist, heavy industry equipment (especially oil and gas extraction). As said industries have matured and diversified geographically, these engineering organisations have moved up the value chain in their respective sectors to position themselves as more holistic service/solution providers. With expertise forged over years of experience, the addition of design-led engineering innovation functions allows companies to extend their services from extraction and infrastructure services, to the development of new engineering processes, capabilities and software around the globe.

\section{LEADERSHIP CHALLENGES}

- How can locally-grown specialist capabilities be successfully repositioned in adjacent industries internationally?

- How can a culture of innovation be fostered in organisations where change has historically been set by top-down senior management mandate?

- How can we reframe a new organisational mission internally, in a way that is palatable to teams and individuals whose capabilities were shaped in a bygone era?

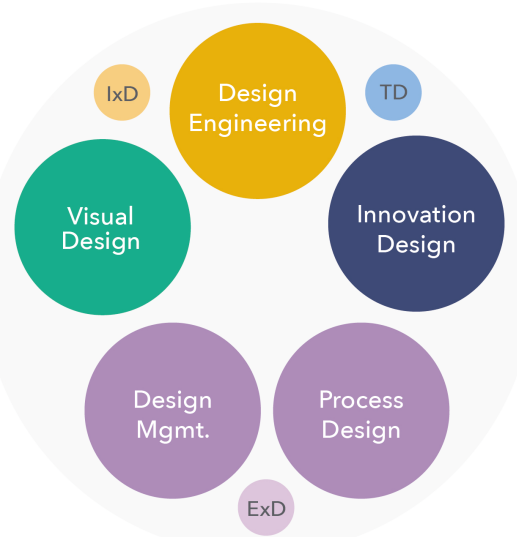




\section{THE EXPERIENCE OPTIMISERS}

\section{DESCRIPTION}

The design champions in the age of customer experience. Bearing some similarities to the Design Transformers, but generally on a smaller scale, these design functions typically play a key role in driving continuous user journey improvement. Almost exclusively found in mature service industries like utilities companies, broadcasters and banks, these design configurations help their organisations compete on experience. Such teams likely have a hand in ensuring customer interactions remain relevant as digital landscapes shift, as well as maintaining digital touchpoints.

\section{LEADERSHIP CHALLENGES}

- How can design efforts be cohered across the organisation to ensure a consistent customer journey?

- How can technical development teams be influenced and empowered to work in a more customer-centric way when design teams are outnumbered?

\section{THE BRAND CHANNELLERS}

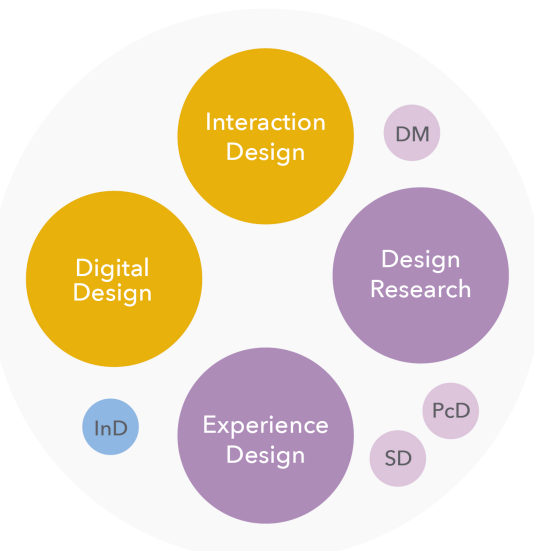

\section{DESCRIPTION}

The brand experience standard-bearers in times of channel proliferation. With examples across broadcast, publishing and retail industries, these design functions likely had their roots in content production - with design capabilities having been brought in-house to cater for a constant need for asset creation close to the source. As these industries have adapted to new technologies in recent decades, their creative needs have further grown to keep pace with the demands of emerging channels. These teams are similar to In-House Agency configurations but distinct for their inclusion of in-house Innovation Design capabilities; with the need to adapt to emerging channels and changing customer behaviours too pressing to leave to external partners.

\section{LEADERSHIP CHALLENGES}

- How can the design workload be balanced between delivering to everyday production cycles and keeping one eye on future opportunities and challenges?

- How can the in-house design process, optimised for a one channel world, be adapted to fit a multi-channel world?

- How can design skills and capabilities be developed and adapted to the ever-shifting production environment?

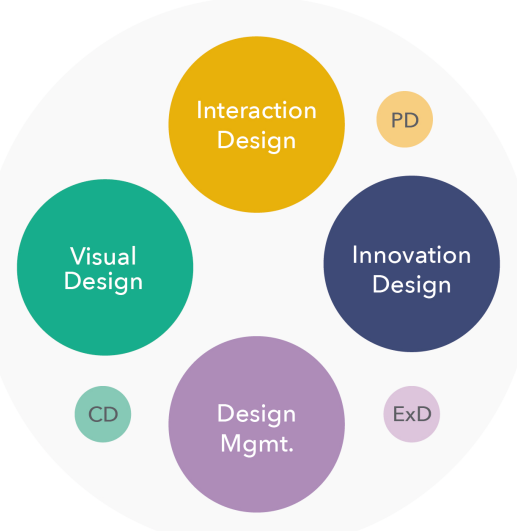




\section{THE DESIGN RESEARCHERS}

\section{DESCRIPTION}

The investigative drivers of organisational user-centricity. These configurations typically pair specialist, in-house user research capabilities with one other sector specific design role. Whilst generally small in size, these functions play a key role in informing front end design processes typically helping highly technically competent organisations inject greater user empathy and understanding into innovation efforts.

\section{LEADERSHIP CHALLENGES}

- How and where should design research resource be deployed within organisations many orders of magnitude bigger than the in-house team?

- How does design bridge the gap between research and organisational action - ensuring research doesn't just produce reports that gather dust?

- How do design researchers shift the culture of their organisation to be more user-focussed, and engage colleagues in the user research process?

\section{THE IN-HOUSE AGENCIES}

\section{DESCRIPTION}

The one-stop-internal-shop for organisations' everyday communications and content needs. With several examples in both insurance and retail, these relatively small design units are generally off-shoots of marketing departments. Less concerned with innovation than the likes of the Brand Channellers, these teams are more geared towards the company's day-to-day, ongoing communication and content production needs. Some of these teams have also likely brought in capabilities to manage and maintain crucial digital touch-points in a cost-efficient way, on-site.

\section{LEADERSHIP CHALLENGES}

- How can some structure be brought to the design briefing process, to increase efficiency and ensure in-house designers don't just serve those who shout loudest?

- How can design efforts be focussed where they can make most impact, when in-house agency time is perceived as free and unlimited?

- How can the design function level up to a more strategic position; helping to frame and initiate strategic content and communications projects?

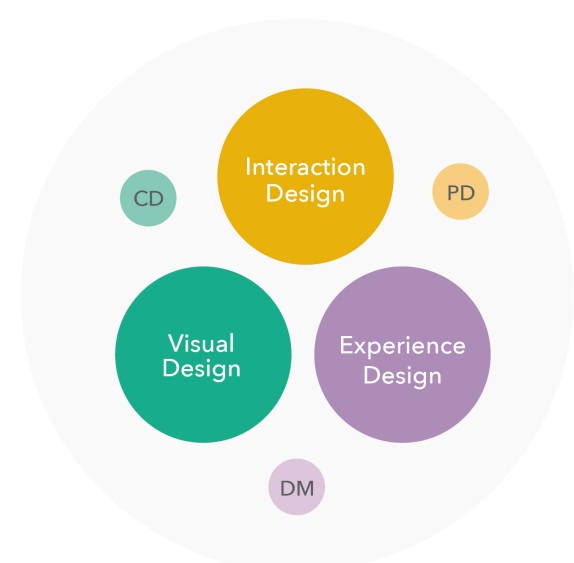

\section{THE HIGH-CRAFT STUDIOS}

\section{DESCRIPTION}

The design curators of high-end manufacturing. Typically co-located with production facilities, 
these small design teams are focussed on the conception and management of premium consumer product portfolios, in industries where product value is often linked to provenance of manufacturing, expert hand-craftsmanship and high-design. Internal design management capability ensures that these businesses allow highly skilled craftspeople to get on with what they're good at - design managers typically handling the interface with the rest of the organisation, as well as external clients buying in the company's manufacturing expertise.

\section{LEADERSHIP CHALLENGES}

- How do designers balance the short-term need to design next season's range with the ability to keep an eye on future trends and changing market dynamics?

- How can designers grab the attention of senior executives to inspire them about the possible future direction the company's brand and product portfolio could take?

- How the needs of designing for our brands and the pressures of supplying external clients be best balanced?

\section{THE DESIGNGINEERS}

\section{DESCRIPTION}

The exclusive and sizeable design engineers club. Common amongst companies concerned with installing, developing or maintaining machinery and technological installations in construction, infrastructure and transportation industries, these specialist engineering design functions are responsible for initiating the design process - either internally, with clients, or both. Acting as a bridge between project needs and specialist engineering teams, design expertise in these companies is channelled towards delivering existing services - not concerned with shaping the company's future offering (as seen with Engineering Innovators)

\section{LEADERSHIP CHALLENGES}

- How can an effective internal project charging structure help these businesses make most efficient use of limited design engineer time?

- How can design engineers best stay up to date with evolving industry standards, regulations, techniques, methods and trends whilst staying on top of day-to-day business?

- How can team capacity be flexed to quickly respond to variable company needs?

\section{EXTRA SMALL}

\section{THE BRAND INNOVATORS}

\section{DESCRIPTION}

The design and innovation guardians of ambitious food and drinks brands. Seen most commonly within alcoholic beverage manufacturers - but also in other food/drinks brands, as well as the occasional retailer - these extra-small design functions have a foot in both execution 
and innovation. Designers in these organisations plays an important role in managing and maintaining brand identity, while also developing the business proposition and portfolio framing how the company diversifies and fuels its new product development pipeline.

\section{LEADERSHIP CHALLENGES}

- How can an effective innovation function and culture be developed in companies where responsibility for innovation has historically sat with founders/ owners?

- How can innovation within the company be moved from an informal, ad-hoc activity to a rigorous, professionalised process supported by organisation-wide capability?

- How can designers help ensure a rapidly growing product portfolio makes sense to retailers and consumers?

\section{THE DESIGN MANAGEMENT GURUS}

\section{DESCRIPTION}

The brave design champions of design-poor environments. Typically comprising just one or two roles, these design managers are seen across a variety of B-2-B and B-2-C companies; from retailers to healthcare providers. Rather than spread responsibilities for design management across job descriptions, these organisations have taken a decision to centralise the capability. These specialised individuals or duos allow the company to effectively and confidently draw on specific design expertise from outside - buying in the design services of agencies and managing freelancers and contractors - whilst retaining enough design knowledge within the company to ensure much needed consistency.

\section{LEADERSHIP CHALLENGES}

- How can a network of trusted design suppliers be built with limited resources?

- How can design managers establish themselves as the go to contact for design queries within the organisation?

- How can design managers get better at educating other teams within the business about the value of design?

\section{THE VISUAL DESIGNERS}

\section{DESCRIPTION}

The graphic design ninjas. With similarities to the In-House Agency model, but on a smaller (often single practitioner) scale, these graphics-orientated design functions cater for the day-today communications need of companies across sectors including retail, professional services and hospitality. These organisations' design needs are likely characterised by a constant demand for professional, quality content and collateral across customer touch-points - making on-site capabilities a necessity. These designers are also likely to be heavily involved in helping 
produce effective internal communications - applying their expertise to things like annual reports, intranets, corporate identities and the employee experience.

\section{LEADERSHIP CHALLENGES}

- How can the perceived value and strategic role of design in the organisation be increased; breaking free from their perceived status as PowerPoint stylists?

- How can design efforts be focussed on where they can make most impact, when in-house visual design time is perceived of as free?

- How structure be brought to the design briefing process - to unlock efficiency and effective prioritisation?

\section{THE LONE INNOVATION RANGERS}

\section{DESCRIPTION}

The chief internal agitators of product and service innovation. Occurring across a breadth of industries - from food and drink, engineering services, oil and gas, agriculture, professional services and consumer packaged goods - these future-facing provocateurs put up a brave one(or occasionally two-) person fight against organisational stagnation. Likely initiating, managing and facilitating new product development efforts and future pipeline scoping, these individuals act as a bridge to join the dots between Marketing and R\&D departments - balancing customer needs with technical capabilities and business viability.

\section{LEADERSHIP CHALLENGES}

- How can the continued relevance of a company's offerings be ensured in the face of tired old 'this is the way things are done around here' mentalities?

- How can colleagues across departments and business units be best empowered to create fertile ground for collaboration and knowledge sharing?

- How can a more structured approach to innovation be best initiated to help align departments to new ways of working?

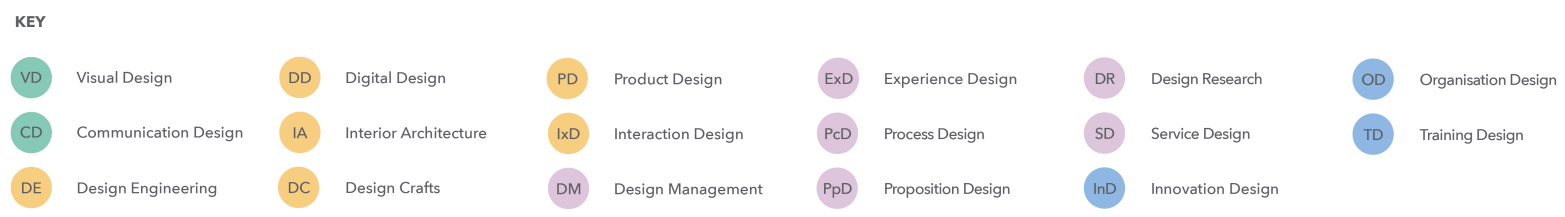




\section{CONCLUSION}

By analysing data on the job titles of over 1,700 people in design roles from within the 500 top companies in Scotland; 17 categories of design role have been identified across economic sectors and company types. By further analysing the scope and prevalence of these roles in each company, 12 design function 'archetypes' have been proposed to bring to life the range of ways in which design roles are concentrated in companies today.

As well as providing a snapshot of the multitude of ways design roles are being organised inhouse today, this work intends to start a discussion and provide the basis for further research into the general population of in house designers; the range of corporate callings design roles are being configured towards, and the challenges of successfully building design capability at the heart of organisations.

In the coming months this research will be extended to include the sizeable number of designers in Scotland working in-house in the public and non-profit sectors; prior to a phase of in-depth interviews with design leaders of companies from each design team archetype to further explore the questions posed in this article. 


\section{AUTHORS}

\section{IAIN AITCHISON}

lain is Founder and Director of Graft, an innovation capability consultancy based in Edinburgh, Scotland, working with a global roster of blue chip clients.

Previously Director at London-based product strategy consultancy Plan, over the last 15 years, he has consulted to clients including Bacardi, Barclays, British Gas, Lenovo, Mars Inc., PepsiCo, Samsung, Unilever, Wrigley's and Yamaha-leading innovation projects in over 15 countries around the world. On a mission to help organisations realise their innovation potential, lain has also helped build several long-term internal education programmes to enhance capabilities of client teams.

Alongside this work he is Programme Director at the Innovation School, Glasgow School of Art and sits on the boards of the Design Management Institute and Creative Scotland, the national body that supports the arts, screen and creative industries.

\section{SAM DUNNE}

Sam is strategist, researcher and writer who consults for a range of international clients including Coloplast, BNP Paribas and Mars Inc. Sam is also Contributing Editor at Core77, reporting on design, innovation, technology and food - contributing occasionally to other titles including Quartz, Gizmodo and MOLD (Food Design/Futures). Sam now works with Graft on a range of innovation assignments to which he brings his research and writing flair.

\section{ESTHER STEINER}

Esther is a design management specialist with a passion for helping clients leverage the potential of design within their organisations. She is a graduate of the BA Design Management International programme at Lucerne University of Applied Sciences where she developed a focus on service design approaches. Prior to joining Graft in 2017, she worked as a Project Manager for a full-service agency in Basel, Switzerland. Previously, Esther consulted on a variety of innovation and design projects with a range of clients, developing strategies and usercentred services that make business sense. 